\title{
SOME HYDRODYNAMIC BOUNDARY LAYER INFLUENCES ON MASS TRANSFER COEFFICIENTS
}

\author{
G.L. FLYNN*+, A.B. FRENCH $§$, N.F.H. HO†, W.I. HIGUCHI ${ }^{\dagger}$, E.A. OSTAFIN, \\ L.H. WARBASSE, G.E. AMIDON and E. WILLIAMS
}

College of Pharmacy ${ }^{\dagger}$ and Department of Internal Medicine $\$$, Medical School, The University of Michigan, Ann Arbor, MI 48109 (U.S.A.)

(Received September 16, 1983; accepted in revised form January 13, 1984)

\section{Summary}

As an initial approach to the quantitative understanding of the importance of various components of intestinal contents as factors in mass transfer resistance, studies have been performed in diffusion cells containing polydimethylsiloxane membranes under circumstances sensitive to the boundary layers. (1) The effect of temperature change on permeability was measured. Under the conditions of the study, demonstration of a clear transition from membrane control to boundary control with rising temperature proved elusive. (2) When membrane thickness was systematically decreased, a gradual transition from membrane to boundary control was demonstrated, yet practical restrictions of the experimental conditions and system limited the degree to which either membrane or diffusion layers could be manipulated into a rate controlling role. (3) The effect of solution viscosit on mass transfer was also studied. Methylcellulose and sucrose were used as polymeric anc low molecular weight viscosity inducing agents respectively. It was readily shown that viscosity has a much greater influence on the flux of a permeant through decreased diffusion coefficients than through increased boundary layer thicknesses, as is predicted by dif fusional theories.

\section{Introduction}

Hydrodynamic boundary layers, sometimes referred to as diffusion layers or unstirred layers, are increasingly being shown as significant in limiting the mass transfer of substances across biological and synthetic membranes [1-4. These appear particularly important in membrane systems separating aqueou phases where the membranes are non-polar or lipid in nature and where the permeating species are hydrophobic [5]. A lipoidal nature is a characteristic of many living membranes, whether of a single cell or a multicellular tissue barrier. Membranes of the latter type include the very permeable gastrointestinal (GI) lining [6], with its single layer of epithelial cells and underlying supporting structure, and the skin [7,8], where a cornified, multilayer epithelium results in relatively limited permeability. These and other mem-

*To whom correspondence should be addressed. 
branes have been or are being studied in our laboratories and regardless of their complexities, conditions have been found for each membrane under which mass transfer across a boundary layer is a limiting factor. In some cases, the boundary layer combines with non-factorable aqueous diffusional resistance within the tissue and the summed diffusional resistance of aqueous nature is surprisingly large.

There are human pathological states in which it appears that hydrodynamic boundary layer resistances should be greatly increased. For instance, in cystic fibrosis, increased production of unusually viscid mucus is believed to interfere with diffusion of nutrients up to the GI membrane, and of oxygen up to and carbon dioxide away from the alveolar membrane of the lung [9]. Because in such diseases mass transfer occurs through media of high viscosity, it becomes necessary to include explicitly the boundary layer viscosity as an additional variable in models of mass transfer events. Previous models of our own and of others have assumed transport through a medium of the fluidity of water. Even the normal intestinal content differs greatly from water in its hydrodynamic characteristics. This solution of mucus and dissolved foodstuffs with its slurry of particulates has a reduced fluidity, the significance and precise characteristics of which have never been determined. Thus, hydrodynamic factors related to viscosity must be studied and put into proper perspective in both normal and pathological states.

In order to study hydrodynamic boundary layer characteristics without the complications imposed by a biological membrane, in vitro studies have been initiated using polydimethylsiloxane membranes with progesterone as the permeant, which seemed ideal for the purposes $[10,11]$. Conditions have been manipulated in several ways in an attempt to demonstrate the transition of a diffusional process from membrane control to boundary layer control. Temperature and membrane thickness effects have been studied in a conventional diffusion cell. More relevant experiments into the properties of the boundary layer were performed in a novel diffusion cell operating on a rotating disk principle. Here the influences of stirring and of medium viscosity on mass transfer have been evaluated.

\section{Experimental}

\section{Materials}

\section{(1) Chemicals}

The permeant in these studies was radiolabeled progesterone. This was obtained as $\left[7(n)-{ }^{3} \mathrm{H}\right]$ progesterone (Amersham/Searle, Arlington Heights, Ill.) with a specific activity of $7.9 \mathrm{Ci} / \mathrm{mmol}$. A limited number of experiments was also performed with $\left[1 \propto, 2 \propto(\mathrm{n})^{3} \mathrm{H}\right]$ progesterone (Amersham/Searle, Arlington Heights, Ill.). Each lot was supplied as a $1 \mathrm{ml}$ benzene solution and was diluted with $95 \%$ ethanol to $12 \mathrm{ml}$ upon receipt. All subsequent solutions were prepared from the ethanol stock solutions. 
Two lots of methylcellulose rated at 15 centipoise (cp) and $100 \mathrm{cp} \mathrm{(2 \%} \mathrm{solu-}$ tions) were obtained and used as received (Methocel A, Dow Chemical, Midland, Mich.). Reagent grade sucrose was used as received. The solutions were prepared from water freshly distilled on the premises.

\section{(2) Membrane choice and preparation}

A two-component room temperature vulcanising polydimethylsiloxane rubber (Silastic 382 Medical Grade Elastomer, Dow Corning, Midland, Mich.) was used to prepare the membranes. This material forms a non-polar continuum and is therefore "lipid-like" in nature. Thus partitioning and membrane diffusion, rather than pore permeation, is the mechanism of mass transfer. In addition, such silicone rubber membranes have been shown to be impermeable to ions and buffers [12] and to be unaffected by the presence of surfactants [13], making it very unlikely that adjuvants used in these studies would affect the nature of the polymer.

Membranes were prepared by mixing catalyst with elastomer base and applying a vacuum to eliminate air bubbles. The elastomer was then applied to both sides of a 50- $\mu \mathrm{m}$ thickness stainless steel support screen with large, circular perforations. Screens with different porosities were used in different studies. In this manner, the stainless steel supporting structures reduced the area for transport within the conventional cell from $10 \mathrm{~cm}^{2}$ total area to $3.38 \mathrm{~cm}^{2}$ available area, while the area within the rotating membrane cell was effectively reduced from the $6.16 \mathrm{~cm}^{2}$ total area to $4.36 \mathrm{~cm}^{2}$. The stainless steel itself was impervious. For the variable membrane thickness and temperature studies, the elastomer was spread evenly over the support screen and flattened into a film by being placed between two heavy granite slabs separated by spacers. For the viscosity studies, one $50-\mu \mathrm{m}$ thick spacer was placed on each side of the 50- $\mu \mathrm{m}$ support screen and the entire unit (spacerscreen-spacer) was compressed in a hydraulic press with 3000 pounds pressure. Upon completion, each membrane was allowed to cure in the press for twelve hours. It was removed and soaked in distilled water for approximately fifteen minutes before use. Finished membranes were measured at several locations with a micrometer to determine their average thicknesses. The support and spacers are each $50 \mu \mathrm{m}$ thick, resulting in a total membrane thickness of approximately $150 \mu \mathrm{m}$ [14]. Early observations using unsupportive membranes in the conventional diffusion cell indicated that thin membranes were set into vibration during the experiment. Experimental results showed that this vibration disturbed the surface hydrodynamics of the membrane. For this reason a rigid supporting structure in the membranes was necessary. Embedding the support in the membrane eliminated hydrodynamic complications which an external support would cause. Preliminary work indicated the thickness of support screen necessary [14]. 


\section{Experimental procedures}

\section{(1) Conventional diffusion cell}

The diffusion cell used in the temperature studies and studies in which membrane thickness was systematically varied has been previously described by Flynn and Smith [15]. Initial experiments with dilute, fluid slurries of progesterone in the donor compartment indicated that the constant, saturrated concentration necessary to obtain a steady state flux could not be maintained within the cell, since membrane uptake and permeation was more rapid than the rate of solution. In order to establish steady state permeation and to circumvent problems of membrane retention, large external reservoirs, $500 \mathrm{ml}$ each, were connected to the donor and receiver compartments. The contents were circulated separately through each of the $15-\mathrm{ml}$ cell compartments at a rate of $20 \mathrm{ml} / \mathrm{min}$ using two separate piston pumps (FMI Metering Pump Model RRP, Fluid Metering Inc., Oyster Bay, N.Y.). One-millilitre samples were withdrawn initially from the donor compartment and from the receiver side at convenient intervals, and placed directly into $20 \mathrm{ml}$ of scintilla tion cocktail (Aquasol, New England Nuclear, Boston, Mass.). The samples were counted in a scintillation counter (Beckman Model LS200, Beckman Instruments, Irvine, Calif.). Checks on the system indicated that under these circumstances, the donor phase concentration was essentially invarient over the course of the experiments and close approximation of the conditions for $\varepsilon$ steady state was achieved.

\section{(2) Rotating membrane cell}

A rotating membrane cell, similar to that originally described by Albery et al. [16], and identical to the model of Amidon [14], was constructed in a local machine shop. Its inner compartment volume is $70 \mathrm{ml}$ and in these expe] iments the cell was placed in a jacketed external compartment of $450 \mathrm{ml}$. The same medium was placed in each compartment with the permeant placed in the inner chamber. The cell is equipped with a variable speed motor (Master Servodyne Model 4445-30, Cole Palmer Instrument Co., Chicago, Ill.), and experiments were performed at speeds ranging from 40 to $300 \mathrm{rpm}$. The latter represented an upper limit on the possible speeds as vortexing was evident at this speed and became more troublesome at higher velocities. The rota tional speed for each experiment was checked and the rate precisely adjusted with a tachometer.

One-hundred-microlitre samples were first withdrawn from the donor and receiver sides to establish initial concentrations; then at intervals from the receiver side to measure flux. The viscosity of some of the solutions necessitatec careful and consistent rinsing of the Eppendorf pipette tips in the $20 \mathrm{ml}$ of scintillation fluid. One millilitre of water was also added to each scintillation vial containing sucrose solutions to prevent crystallization. 


\section{(3) Solution preparation, and viscosity and density estimation}

Solutions of methylcellulose were prepared according to instructions provided by the supplier [17]. Solutions of $2 \%$ and $1.5 \%$ were prepared on a weight to weight basis by first dispersing the powder in 20-30\% of the water heated to $80-90^{\circ} \mathrm{C}$, stirring thoroughly, then adding the remainder of the water cold. Solution was completed by constant stirring in a refrigerated chamber. Since methylcellulose solutions are not Newtonian in character, the viscosities (centipoise) of $13 \mathrm{cp}$ ( $2 \%$ solution of $15 \mathrm{cp}$ stock), $40 \mathrm{cp}$ ( $1.5 \%$ solution of $100 \mathrm{cp}$ stock) and $100 \mathrm{cp}$ ( $2 \%$ solution of $100 \mathrm{cp}$ stock) were determined by nomography [17]. No attempt was made to correct these for non-Newtonian characteristics of the formed solutions under the conditions of shear of the experiments. The viscosity range was chosen to provide for at least a two-fold increase in the hydrodynamic barrier based on the theoretical assumption that the boundary layer thickness is proportional to macroscopic viscosity to the one-six th power [18]. It was reasoned that the microscopic viscosity would be little affected by the polymer in so dilute a concentration, and therefore the diffusivity of progesterone should not deviate in these solutions appreciably from its diffusivity in water.

Sucrose solutions were prepared on a weight by weight basis to concentrations of $5 \%, 10 \%, 20 \%, 40 \%$ and $60 \%$. Kinematic viscosities of sucrose solutions were measured using calibrated Canon-Fenski version Ostwald viscometers, size $\mathbf{7 5}$ for solutions from 1.6 to 8 centistokes (cs) and size 150 for solutions from 7 to $35 \mathrm{cs}$. Appropriate sized samples were drawn into the viscometers using suction and were allowed to equilibrate to $37^{\circ} \mathrm{C}$ for approximately ten minutes. Efflux times were measured in triplicate and were multiplied by the provided viscometer constants to yield kinematic viscosities. The solutions were prepared and used immediately, and there was never evidence of growth of microorganisms.

Densities were measured by equilibrating and weighing the various sucrose solutions in a standard pycnometer at $37^{\circ} \mathrm{C}$. Agreement with literature values for density was within $0.3 \%$.

\section{Permeability data analysis}

\section{(1) Conventional diffusion cell}

Measured values of samples from the receiver were plotted as counts as a function of time. The overall permeability coefficient, $P$, was calculated from the slopes of the steady state portions of the curves according to:

$P=\frac{V_{\mathrm{r}}(\mathrm{d} C / \mathrm{d} t)}{A \Delta C}$

where $V_{\mathrm{r}}$ is the receiver compartment volume, $(\mathrm{d} C / \mathrm{d} t)$ the rate of change of concentration (counts $/ \mathrm{cm}^{3}$ - $\mathrm{min}$ ) in the receiver compartment, $A$ the area available for diffusion through the membrane, and $\Delta C$ the concentration (counts $/ \mathrm{cm}^{3}$ ) difference across the membrane. This was taken as the donor 
concentration since the receiver accumulation was never a significant fraction of the donor phase.

The barrier layers through which diffusion occurs include the membrane and fluid boundary layers on each side of the membrane, which can be assumed to be essentially of equal thickness due to the symmetry of the cell design. The total diffusional resistance is therefore:

$R_{\mathrm{t}}=2 R_{\mathrm{aq}}+R_{\mathrm{m}}$

and according to Flynn et al. [5], the operative permeability coefficient is the reciprocal of the total resistance as expressed in:

$P=\frac{1}{R_{\mathrm{t}}}=\frac{D_{\mathrm{m}} D_{\mathrm{aq}} K_{\mathrm{m} / \mathrm{aq}}}{D_{\mathrm{m}} K_{\mathrm{m} / \mathrm{aq}} \Sigma h_{\mathrm{aq}}+D_{\mathrm{aq}} h_{\mathrm{m}}}$

where subscripts $m$ and aq stand for membrane and water (boundary layer), respectively, $D$ symbolizes diffusivity, $h$ represents thickness, $\Sigma h_{\text {aq }}$ is the combined thickness of the two boundary layers, and $K_{\mathrm{m} / \mathrm{aq}}$ is the membranewater partition coefficient.

In the temperature studies, it was initially assumed that $D_{\mathrm{m}}$ would have a far greater sensitivity to temperature than $D_{\text {aq }}$, as a manifestation of higher activation energy. Equation (4) expresses the presumed relationship of diffusivity to temperature:

$D_{\mathrm{i}}=D_{\mathrm{i}}^{\circ} \mathrm{e}^{-E_{\mathrm{i}} / R T}$

Substitution of this expression into eqn. (3) for each $D$ value and assuming the activation energy, $E_{\mathrm{i}}$, for the membrane to be greater than for the boundary layers, yields a function in which there is a change from membrane to diffusion layer control of $P$ as the temperature is raised. In order to correct for the slight differences in membrane thickness in the temperature studies from run to run, a thickness normalized parameter, $K_{\mathrm{n}}$, was calculated:

$K_{\mathrm{n}}=P h_{\mathrm{m}}$

Close examination of eqn. (3) reveals that eqn. (5) is only an approximate normalization of the membrane thickness variation, as it ignores the boundary layer involvement.

\section{(2) Rotary membrane cell}

Data for the rotary membrane cell, which had different donor and receiver compartmental volumes, $70 \mathrm{ml}$ and $450 \mathrm{ml}$ respectively, were analysed differently. In this case the loss of progesterone from the donor compartment into the receiver, maintained essentially as a sink, was computed from receiver compartment data. The relative concentration of material in the donor compartment at any time after the membrane gradient is formed, $C_{\mathrm{d}}^{\mathrm{t}}$, would be [14]: 
$C_{\mathrm{d}}^{\mathrm{t}}=C_{\mathrm{d}}^{\circ}-C_{\mathrm{r}}^{\mathrm{t}}\left(\frac{450}{70}\right)$

and the first-order rate of loss from the donor side would follow [5,14]:

$\ln \left(\frac{C_{\mathrm{d}}^{\mathrm{t}}}{C_{\mathrm{d}}^{\circ}}\right)=-K_{\mathrm{u}} t$

where the subscripts $d$ and $r$ stand for donor and receiver, respectively. The ratio $450 / 70$ is a concentration adjustment for the respective volumes of the cell halves. $K_{\mathfrak{u}}$, the first ordinate constant, was determined from semilog plots of the data and $P$ evaluated as:

$P=\frac{K_{\mathrm{u}} V_{\mathrm{d}}}{A}$

$V_{\mathrm{d}}$ was $70 \mathrm{ml}$ and the area available was $4.36 \mathrm{~cm}^{2} . K_{\mathrm{u}}$ has the unit of reciprocal time and $P$ the units of $\mathrm{cm} /$ time (velocity).

The hydrodynamic flow at a rotating surface has been characterized by Levich [18]. The aqueous diffusion layer is mathematically described by:

$h_{\mathrm{aq}}=0.6424 \nu^{1 / 6} D_{\mathrm{aq}}^{1 / 3} S^{-1 / 2}$

where $h_{\mathrm{aq}}$ is the thickness of the individual boundary layer, $v$ is the kinematic viscosity and $S$ is the velocity of rotation in revolutions per second. Thus the total resistance across the barrier in the rotating cell can be stated as $[5,14]$ :

$R_{\mathrm{t}}=\frac{2\left(0.6424 v^{1 / 6} D_{\mathrm{aq}}^{1 / 3} S^{-1 / 2}\right.}{D_{\mathrm{aq}}}+\frac{1}{P_{\mathrm{m}}}$

The first term represents the resistance of the two boundary layers, $2 R_{\text {aq }}$, and the second the resistance of the membrane, $R_{\mathrm{m}}$. Like the membrane term, the boundary layer term is the reciprocal of the boundary layer permeability coefficient for two diffusion layers, $2 / P_{\mathrm{aq}}$.

Since $P$ is equal to the reciprocal of the total resistance, it follows from eqns. (7) and (10) that:

$\frac{1}{K_{\mathrm{u}}}=\frac{V_{\mathrm{d}}}{A}\left[\frac{\left(1.285 \nu^{1 / 6}\right) S^{-1 / 2}}{D_{\mathrm{aq}}^{2 / 3}}+\frac{1}{P_{\mathrm{m}}}\right]$

and a plot of the reciprocal rate against the reciprocal of the square root of the rotational velocity should be linear with a slope of $1.285 V_{\mathrm{d}} \nu^{1 / 6} / A D_{\mathrm{aq}}^{2 / 3}$ and an intercept of $V_{\mathrm{d}} / A P_{\mathrm{m}}$. The permeability coefficient of the membrane, $P_{\mathrm{m}}$, has the value $D_{\mathrm{m}} K_{\mathrm{m} / \mathrm{aq}} / h_{\mathrm{m}}$. 


\section{TABLE 1}

Progesterone diffusion across $700-\mu \mathrm{m}$ thick silicone rubber membranes as a function of temperature

\begin{tabular}{|c|c|c|c|c|c|}
\hline $\begin{array}{l}\text { Temperature } \\
\left({ }^{\circ} \mathrm{C}\right)\end{array}$ & $\begin{array}{l}\text { Lag } \\
\text { time } \\
\text { (min) }\end{array}$ & $\begin{array}{l}\text { Membrane } \\
\text { thickness, } h \\
(\mathrm{~cm})\end{array}$ & $K_{\mathrm{n}}\left(\mathrm{cm}^{2} / \mathrm{min}\right)$ & $\begin{array}{l}\text { Permeability } \\
\text { coefficient } \\
(\mathrm{cm} / \mathrm{min})\end{array}$ & $\begin{array}{l}\text { Apparent } \\
\text { diffusivity }^{a} \\
\left(\mathrm{~cm}^{2} / \mathrm{sec}\right)\end{array}$ \\
\hline 75 & 13 & 0.0697 & $1.62 \times 10^{-5}$ & $3.45 \times 10^{-2}$ & $1.04 \times 10^{-6}$ \\
\hline 75 & 13 & 0.0670 & $1.49 \times 10^{-5}$ & $3.29 \times 10^{-2}$ & $9.59 \times 10^{-5}$ \\
\hline 60 & 12 & 0.0717 & $1.16 \times 10^{-5}$ & $2.40 \times 10^{-2}$ & $1.19 \times 10^{-6}$ \\
\hline 60 & - & 0.0727 & $1.18 \times 10^{-5}$ & $2.41 \times 10^{-2}$ & - \\
\hline 50 & 32 & 0.0735 & $1.10 \times 10^{-5}$ & $2.21 \times 10^{-2}$ & $4.69 \times 10^{-7}$ \\
\hline 50 & 28 & 0.0727 & $1.10 \times 10^{-5}$ & $2.25 \times 10^{-2}$ & $5.24 \times 10^{-7}$ \\
\hline 45 & 31 & 0.0697 & $8.50 \times 10^{-6}$ & $1.80 \times 10^{-2}$ & $4.35 \times 10^{-7}$ \\
\hline 45 & 29 & 0.0697 & $7.66 \times 10^{-6}$ & $1.63 \times 10^{-2}$ & $4.65 \times 10^{-7}$ \\
\hline 37 & 36 & 0.0697 & $7.50 \times 10^{-6}$ & $1.59 \times 10^{-2}$ & $3.75 \times 10^{-7}$ \\
\hline 37 & 32 & 0.0727 & $7.25 \times 10^{-6}$ & $1.48 \times 10^{-2}$ & $4.59 \times 10^{-7}$ \\
\hline 30 & 42 & 0,0697 & $6.52 \times 10^{-6}$ & $1.38 \times 10^{-2}$ & $3.21 \times 10^{-7}$ \\
\hline 30 & 35 & 0.0670 & $6.03 \times 10^{-6}$ & $1.33 \times 10^{-2}$ & $3.56 \times 10^{-7}$ \\
\hline 25 & 52 & 0.0735 & $6.02 \times 10^{-6}$ & $1.21 \times 10^{-2}$ & $2.89 \times 10^{--9}$ \\
\hline 25 & 55 & 0.0727 & $6.54 \times 10^{-6}$ & $1.33 \times 10^{-2}$ & $2.67 \times 10^{-7}$ \\
\hline 20 & 52 & 0.0670 & $4.74 \times 10^{-6}$ & $9.87 \times 10^{-3}$ & $2.40 \times 10^{-7}$ \\
\hline 20 & 55 & 0.0696 & $5.02 \times 10^{-6}$ & $1.07 \times 10^{-2}$ & $2.45 \times 10^{-7}$ \\
\hline 10 & 61 & 0.0670 & $3.43 \times 10^{-6}$ & $7.58 \times 10^{-3}$ & $2.04 \times 10^{-7}$ \\
\hline 10 & 62 & 0.0717 & $3.43 \times 10^{-6}$ & $7.08 \times 10^{-3}$ & $2.30 \times 10^{-7}$ \\
\hline \multicolumn{6}{|c|}{ T.J. Roseman's data [10] } \\
\hline 37 & 22.0 & 0.0597 & - & - & $4.50 \times 10^{-7}$ \\
\hline 37 & 12.8 & $\begin{array}{l}0.0516 \\
\quad \text { fillerless) }\end{array}$ & - & - & $5.78 \times 10^{-1}$ \\
\hline
\end{tabular}

a The apparent diffusivity is based on the Daynes and Barrer lag time equation, $t_{\mathrm{L}}=h^{2} / 6 D$.

\section{Results}

Data obtained in the temperature studies are summarized in Table 1, which indicates the temperature, the thickness of the membrane, the permeability coefficient, $P$, the lag time, the $K_{\mathrm{n}}$ value, and finally, the apparent diffusion coefficient estimated from the lag time for each run. In Fig. 1 the thicknessnormalized rate constants, $K_{\mathrm{n}}$ values, for membranes all about $700 \mu \mathrm{m}$ thick $(715 \mu \mathrm{m} \pm 5$; range $670-735 \mu \mathrm{m})$ are plotted semi-logarithmically against the reciprocal of the absolute temperature. This membrane thickness was selected to allow an estimated $50 \%$ boundary layer contribution to the mass transfer resistance at $37^{\circ} \mathrm{C}$. This estimate was based on a reported effective diffusion layer thickness of $188 \mu \mathrm{m}$ for the cell [19] and on diffusion parameters for progesterone in the membrane given by Roseman [10].

A representative set of permeation profiles for studies run as a function of membrane thickness is shown in Fig. 2 and these indicate the gross steady 

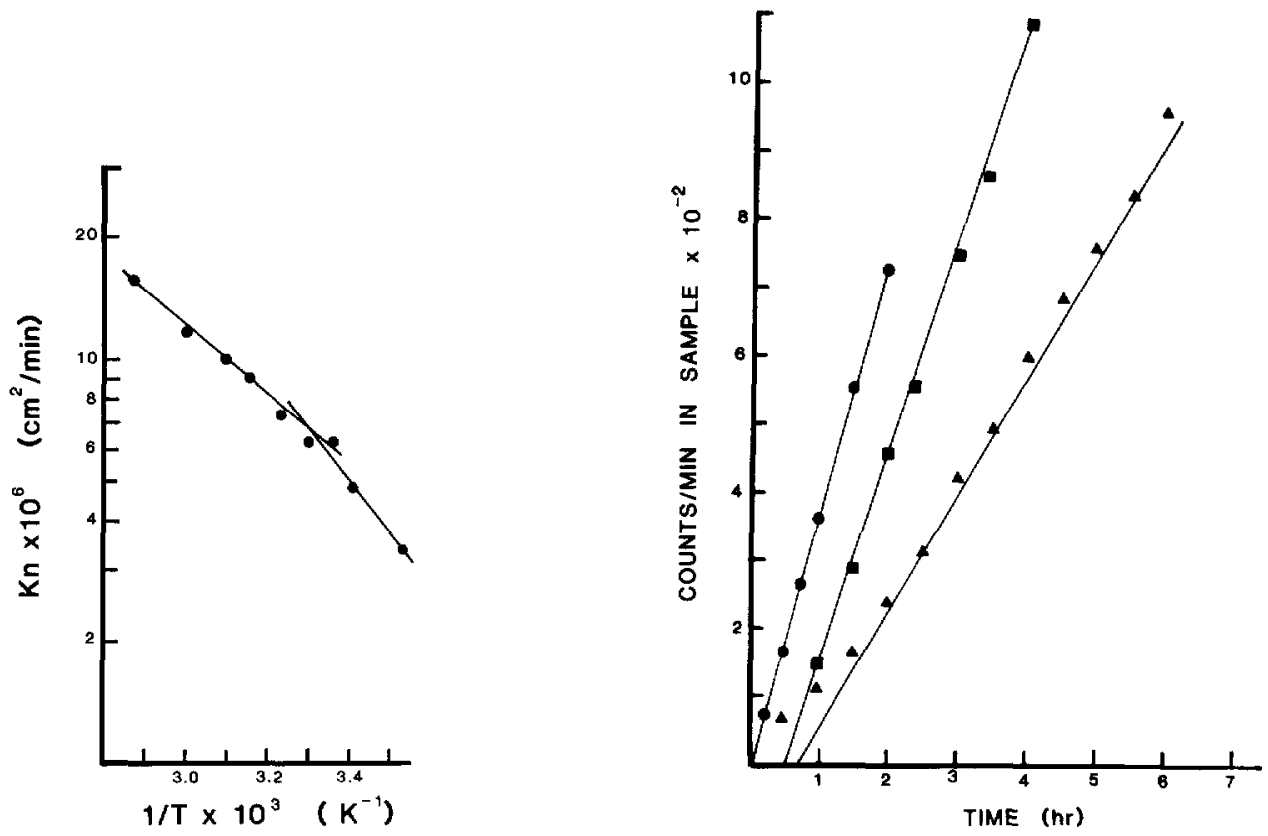

Fig. 1. Arrhenius-like plot of the membrane thickness normalized rate constants, $K_{\mathrm{n}}$, for $700-\mu \mathrm{m}$ membranes. Biexponential character is evident in the profile, which suggests a transition from membrane to diffusion layer control as the temperature is raised.

Fig. 2. Permeation profiles for membranes $155 \mu \mathrm{m}(\bullet), 630 \mu \mathrm{m}(\bullet)$ and $950 \mu \mathrm{m}(4)$ in thickness. All data were obtained at $37^{\circ} \mathrm{C}$.

state flux and lag time dependencies of the experiments. Data are presented in Table 2 for experiments performed at $37^{\circ} \mathrm{C}$ using membranes varying in thickness from $155 \mu \mathrm{m}$ to $950 \mu \mathrm{m}$. The manner in which the permeability coefficient decreases as the reciprocal thickness is increased is seen in Fig. 3.

Table 3 contains the results of partitioning studies, including the previous results of another investigator [10]. All data indicate the value of the partition coefficient for progesterone between the polydimethylsiloxane matrix and water to be about fifty $(47.7 \pm 4.61)$ at $37^{\circ} \mathrm{C}$, irrespective of method of estimation, the presence or absence of filler, or the concentration of progesterone equilibrated.

A set of permeation profiles (20\% sucrose solutions) obtained at different rotational speeds with the rotating membrane apparatus is given in Fig. 4 . The curvilinear nature of these plots is real, as the donor phase concentration decreases significantly over the course of a run. However, aided by dilution into the larger volume of the receiver, the essence of sink conditions is nevertheless maintained and the method of data processing implicit in eqn. (6) linearizes the results and yields valid estimates of the rate constant, $K_{\mathrm{u}}$. In these studies the membrane was preloaded with progesterone and the collection of samples begun after the steady state had been obtained. The limited number of counts 


\section{TABLE 2}

Permeation of progesterone through silicone rubber membranes as a function of membrane thickness at $37^{\circ} \mathrm{C}$

\begin{tabular}{|c|c|c|c|c|}
\hline $\begin{array}{l}\text { Membrane } \\
\text { thickness } \\
\text { (cm) }\end{array}$ & $\begin{array}{l}\text { Lag } \\
\text { time } \\
(\min )\end{array}$ & $\begin{array}{l}\text { Permeability } \\
\text { coefficient } \\
(\mathrm{cm} / \mathrm{min})\end{array}$ & $\begin{array}{l}\text { Average } \\
\text { permeability } \\
\text { coefficient }\end{array}$ & $\begin{array}{l}\text { Apparent } \\
\text { diffusivity } \\
\left(\mathrm{cm}^{2} / \mathrm{sec}\right)\end{array}$ \\
\hline $\begin{array}{l}0.0155 \\
0.0155 \\
0.0175 \\
0.0175 \\
0.0210 \\
0.0210 \\
0.0265 \\
0.0265 \\
0.0330 \\
0.0375 \\
0.0450 \\
0.0450 \\
0.0630 \\
0.0830 \\
0.0830 \\
0.0950 \\
0.0950 \\
\text { Computer }\end{array}$ & $\begin{array}{c}6 \\
3 \\
6 \\
6 \\
7 \\
5 \\
9 \\
9 \\
12 \\
15 \\
13 \\
18 \\
35 \\
42 \\
40 \\
49 \\
41 \\
\text { mate b }\end{array}$ & $\begin{array}{l}3.66 \times 10^{-2} \\
3.39 \times 10^{-2} \\
3.28 \times 10^{-2} \\
3.07 \times 10^{-2} \\
3.14 \times 10^{-2} \\
3.02 \times 10^{-2} \\
2.73 \times 10^{-2} \\
2.99 \times 10^{-2} \\
2.79 \times 10^{-2} \\
2.44 \times 10^{-2} \\
2.23 \times 10^{-2} \\
2.27 \times 10^{-2} \\
1.92 \times 10^{-2} \\
1.50 \times 10^{-2} \\
1.56 \times 10^{-2} \\
1.35 \times 10^{-2} \\
1.50 \times 10^{-2}\end{array}$ & $\begin{array}{l}3.52 \times 10^{-2} \\
3.18 \times 10^{-2} \\
3.08 \times 10^{-2} \\
2.86 \times 10^{-2}\end{array}$ & $\begin{array}{l}1.11 \times 10^{-7} \\
2.22 \times 10^{-7} \\
1.42 \times 10^{-7} \\
1.42 \times 10^{-1} \\
1.75 \times 10^{-7} \\
2.45 \times 10^{-7} \\
2.17 \times 10^{-7} \\
2.17 \times 10^{-7} \\
2.52 \times 10^{-7} \\
2.60 \times 10^{-7} \\
4.33 \times 10^{-7} \\
3.13 \times 10^{-7} \\
3.15 \times 10^{-7} \\
4.55 \times 10^{-7} \\
4.78 \times 10^{-7} \\
5.12 \times 10^{-7} \\
6.12 \times 10^{-7} \\
6.92 \times 10^{-7}\end{array}$ \\
\hline
\end{tabular}

a The apparent diffusivity is based on the Daynes and Barrier lag time equation, $t_{\mathrm{L}}=h^{2} / 6 D$.

${ }^{b}$ Based upon a partition coefficient, $K_{\mathrm{m} / \mathrm{aq}}$, of 47.7 ; see discussion of Fig. 3 .

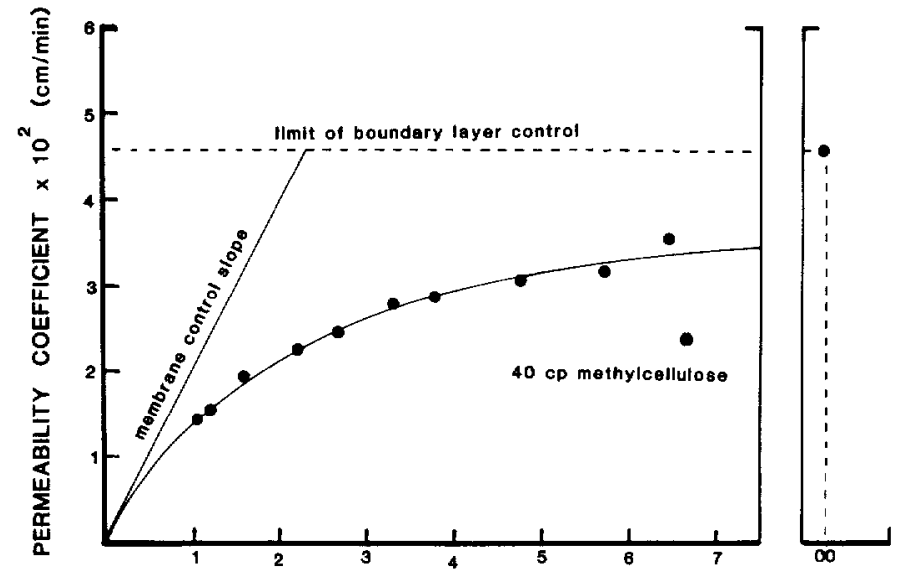

RECIPROCAL MEMBRANE THICKNESS $1 / \mathrm{h} \times 10^{-1}\left(\mathrm{~cm}^{-1}\right)$ 


\section{TABLE 3}

Partitioning of progesterone into silicone rubber

\begin{tabular}{|c|c|c|c|}
\hline $\begin{array}{l}\text { \% Saturation } \\
\text { progesterone }\end{array}$ & Membrane type & Method of calculation & $\begin{array}{l}\text { Partition coefficient, } \\
K_{\mathrm{m} / \mathrm{aq}}\end{array}$ \\
\hline $25 \%$ & $\begin{array}{l}\text { Silastic }{ }^{d} \\
382 \text { elastomer }\end{array}$ & $\begin{array}{l}\text { Depletion of aqueous } \\
\text { phase }\end{array}$ & 45 \\
\hline $25 \%$ & $\begin{array}{l}\text { Silastic }{ }^{d} \\
382 \text { elastomer }\end{array}$ & $\begin{array}{l}\text { Measured amount in } \\
\text { silicone rubber phase }\end{array}$ & 44 \\
\hline $75 \%$ & $\begin{array}{l}\text { Silastic }^{d} \\
382 \text { elastomer }^{-}\end{array}$ & $\begin{array}{l}\text { Depletion of aqueous } \\
\text { phase }\end{array}$ & 56 \\
\hline $75 \%$ & $\begin{array}{l}\text { Silastic }^{d} \\
382 \text { elastomer }\end{array}$ & $\begin{array}{l}\text { Measured amount in } \\
\text { silicone rubber phase }\end{array}$ & 46 \\
\hline $100 \%$ a b & $\begin{array}{l}\text { Fillerless } \\
\text { polydimethyl- } \\
\text { siloxane }\end{array}$ & $\begin{array}{l}\text { Measured amount in } \\
\text { silicone rubber phase }\end{array}$ & 45 \\
\hline \multirow[t]{2}{*}{$100 \%^{a}$} & $\begin{array}{l}\text { Silastic }^{d} \\
382 \text { elastomer }^{-}\end{array}$ & $\begin{array}{l}\text { Measured amount in } \\
\text { silicone rubber phase }\end{array}$ & 50.2 \\
\hline & & Average & $47.7 \pm 4.61^{c}$ \\
\hline
\end{tabular}

a T.J. Roseman [10].

b Special fillerless material obtained as a gift from Dow Corning, Midland, Mich.

c Coefficient of variation $9.6 \%$.

${ }^{\mathrm{d}}$ Silastic is the trade name for silicone rubber of Dow Corning, Midland, Mich.

representing material which crossed the membrane prior to the setting of time zero was subtracted as background. This procedure was adopted because the lag time could be estimated only for the first experiment in a set and therefore was not a generally useful comparative parameter. For each set of experiments, a plot of $1 / K_{\mathrm{u}}$ versus $S^{-1 / 2}$ was made (eqn. 1 ) and the slope obtained.

A family of curves for sucrose solutions ranging in concentration from $0 \%$ to $60 \% \mathrm{w} / \mathrm{w}$ is found in Fig. 5. The slopes calculated for these runs are pre-

Fig. 3. Permeability coefficients at $37^{\circ} \mathrm{C}$ plotted against the reciprocal of membrane thickness. The straight solid line indicates the trend expected for membrane control. The point to the far right at $1 / h_{\mathrm{m}}=\infty$ is the computer estimate of the diffusion layer control permeability coefficient $\left(4.59 \times 10^{-2} \mathrm{~cm} / \mathrm{min}\right)$. The curvilinear line is the computer best fit line to the data. The singular point (hexagonal) in the lower right quadrant of the plot is a permeability coefficient obtained in a $40 \mathrm{cp}$ methylcellulose solution and shows the effect of increased macroscopic viscosity on the permeation rate. These data can also be plotted as $1 / P$ versus $h_{\mathrm{m}}$ to obtain a straight line $(r=0.992)$ with an intercept, $1 / P_{\mathrm{aq}}$, equal to 21.1 $\left(P_{\mathrm{aq}}=4.74 \times 10^{-2} \mathrm{~cm} / \mathrm{min}\right)$ and a slope, $1 / K D_{\mathrm{m}}$, equal to $5.21 \times 10^{2}\left(K D_{\mathrm{m}}=1.92 \times 10^{-3}\right.$ $\mathrm{cm}^{2} / \mathrm{min}$ ). These values are in close agreement with values from the non-linear computer fit to the curve as displayed. 

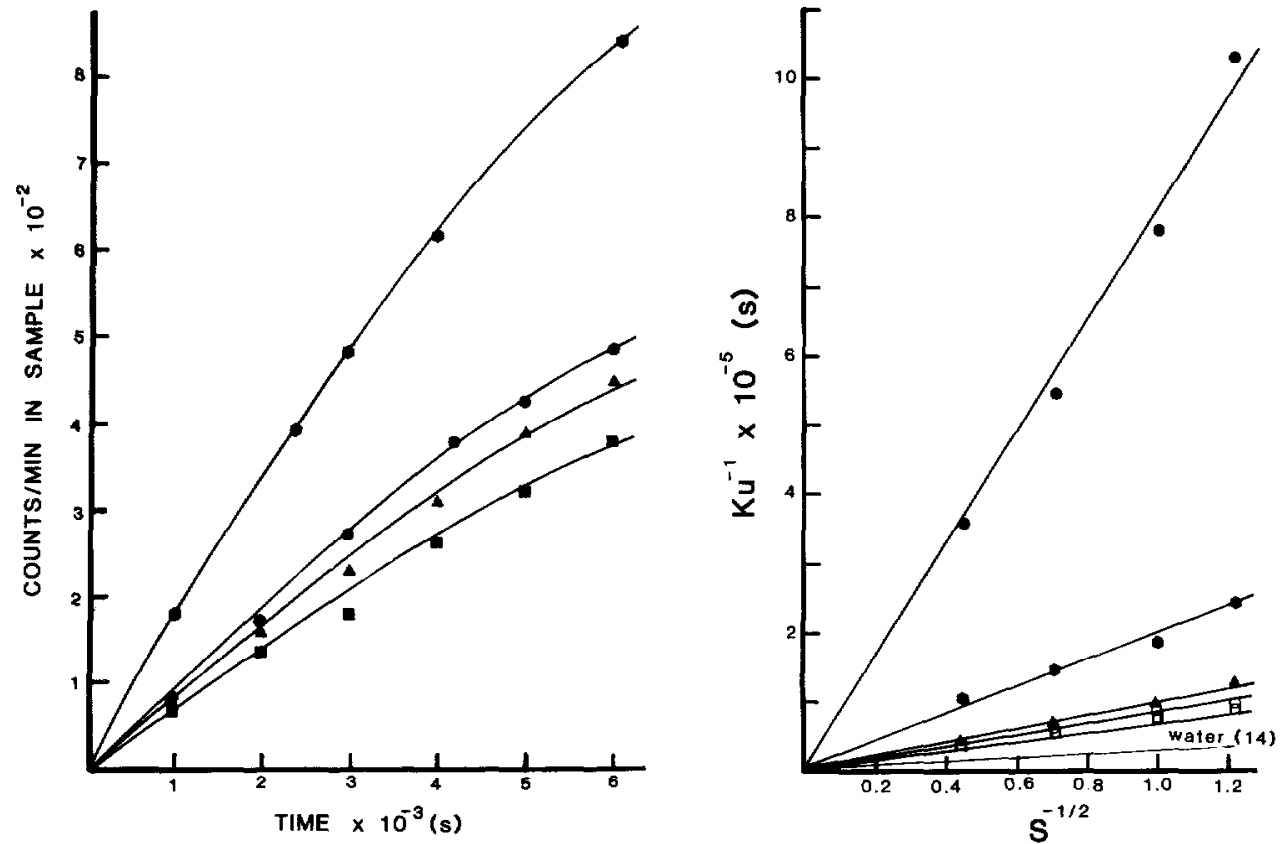

Fig. 4. Raw data $\left(37^{\circ} \mathrm{C}\right)$ for the rotating membrane cell. Solutions were $20 \% \mathrm{w} / \mathrm{w}$ sucrose. The counts per minute in the receiver compartment are recorded as a function of time.

Fig. 5. Plots of the reciprocal of the rate constant, $K_{\mathrm{u}}^{-1}$, versus the reciprocal square root of the stirring velocity, $S^{-1 / 2}$, for sucrose solutions. The lower line with no data points is the trend for water. The other lines in increasing degree of slope are for $5 \% \mathrm{w} / \mathrm{w}(\square), 10 \%$ $\mathrm{w} / \mathrm{w}(0), 20 \% \mathrm{w} / \mathrm{w}(4), 40 \% \mathrm{w} / \mathrm{w}(\bullet)$ and $60 \% \mathrm{w} / \mathrm{w}(\bullet)$ solutions, respectively. The intercept for water of $7.3 \times 10^{3} \mathrm{sec}$ is barely perceptible on the plot and the intercepts for the sucrose solutions should be even less. All lines pass comfortably through an intercept near 0,0 .

\section{TABLE 4}

Permeation of progesterone through polydimethylsiloxane in the rotating membrane system with water and sucrose solutions as the external media at $37^{\circ} \mathrm{C}$

\begin{tabular}{|c|c|c|c|c|c|c|}
\hline $\begin{array}{l}\% \\
\text { Sucrose }\end{array}$ & $\begin{array}{l}\text { Medium } \\
\text { density } \\
\left(\mathrm{g} / \mathrm{cm}^{3}\right)\end{array}$ & $\begin{array}{l}\text { Medium } \\
\text { viscosity } \\
\text { (cp) }\end{array}$ & $\begin{array}{l}\text { Experimental } \\
\text { slope }{ }^{a} \\
\left(S^{1 / 2} \times 10^{4}\right)\end{array}$ & $\begin{array}{l}\text { Theoretical } \\
\text { slope } \\
\left(S^{1 / 2} \times 10^{4}\right)\end{array}$ & $\begin{array}{l}\text { Experimental } \\
\text { to } \\
\text { theoretical } \\
\text { slope ratio }\end{array}$ & $\begin{array}{l}\text { Actual ratio of } \\
\text { slope to } \\
\text { slope of water }\end{array}$ \\
\hline 0 & 0.9930 & 0.71 & 2.3 & 2.54 & 0.91 & - \\
\hline 5 & 1.0276 & 0.813 & $\begin{array}{l}5.9(1) \\
6.6(2)\end{array}$ & 2.83 & $\begin{array}{l}2.08 \\
2.33\end{array}$ & $\begin{array}{l}2.56 \\
2.87\end{array}$ \\
\hline 10 & 1.0478 & 0.941 & $\begin{array}{l}6.8(1) \\
7.3(2)\end{array}$ & 3.18 & $\begin{array}{l}2.13 \\
2.30\end{array}$ & $\begin{array}{l}2.96 \\
3.17\end{array}$ \\
\hline 20 & 1.0750 & 1.30 & $\begin{array}{r}10.2(1) \\
9.7(2)\end{array}$ & 4.15 & $\begin{array}{l}2.45 \\
2.34\end{array}$ & $\begin{array}{l}4.43 \\
4.22\end{array}$ \\
\hline 40 & 1.1751 & 3.72 & $\begin{array}{l}16.9(1) \\
16.7(2)\end{array}$ & 9.81 & $\begin{array}{l}1.72 \\
1.70\end{array}$ & $\begin{array}{l}7.35 \\
7.26\end{array}$ \\
\hline 60 & 1.2010 & 23.45 & $\begin{array}{l}79.4(1) \\
87.4(2)\end{array}$ & 45.4 & $\begin{array}{l}1.75 \\
1.93\end{array}$ & $\begin{array}{l}34.3 \\
38.0\end{array}$ \\
\hline
\end{tabular}

The slope for each complete experiment in the sucrose solutions is listed separately. Each was determined from data at the indicated four rotational speeds.

${ }^{b}$ The theoretical slopes were calculated using eqn. (20) which requires knowledge of only the medium viscosity and density. The theoretical $37^{\circ} \mathrm{C}$ slope is thus $1.57 \times 10^{6} \xi^{5 / 6} / \rho^{1 / 6}$, where the viscosity is in pois 
TABLE 5

Permeation of progesterone through polydimethylsiloxane membranes in rotating membrane system with methylcellulose solutions as external media at $37^{\circ} \mathrm{C}$

\begin{tabular}{|c|c|c|c|c|c|}
\hline $\begin{array}{l}\text { Solution } \\
\text { composition }\end{array}$ & $\begin{array}{l}\text { Apparent } \\
\text { viscosity } \\
\text { (cD) }\end{array}$ & $\begin{array}{l}\text { Experimental } \\
\text { slope } \\
\left(S^{1 / 2} \times 10^{4}\right)\end{array}$ & $\begin{array}{l}\text { Theoretical } \\
\text { slope } b \\
\left(S^{1 / 2} \times 10^{4}\right)\end{array}$ & $\begin{array}{l}\text { Experimental } \\
\text { to } \\
\text { theoretical } \\
\text { slope ratio }\end{array}$ & $\begin{array}{l}\text { Actual ratio of } \\
\text { slope to slope } \\
\text { of water }\end{array}$ \\
\hline $\begin{array}{l}\text { Water (control) } \\
2 \% \text { Methylcellulose } \\
\text { 2\% Methylcellulose } \\
\text { 2\% Methylcellulose }\end{array}$ & $\begin{array}{l}0.71 \\
13 \\
40 \\
100\end{array}$ & $\begin{aligned} & 2.3 \\
& \sim-9 \\
& \sim 11\end{aligned}$ & $\begin{array}{c}2.54 \\
29 \\
73 \\
157\end{array}$ & $\begin{aligned} & 0.91 \\
& \sim 0.3 \\
& \sim 0.15 \\
& \sim 0.09\end{aligned}$ & $\begin{array}{l}- \\
3.9 \\
4.8 \\
6.1\end{array}$ \\
\hline
\end{tabular}

${ }^{a}$ The calculation uses eqn. (20) and is based on an assumed density of $1.0 \mathrm{~g} / \mathrm{cm}^{3}$. This introduces little error given the slope's negative one-sixth-power dependency on density.

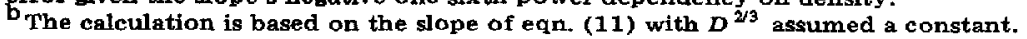

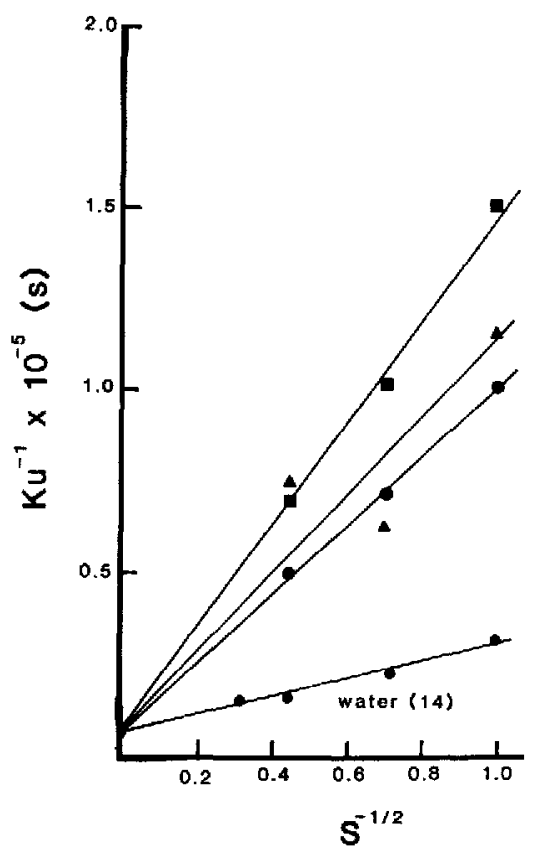

Fig. 6. Reciprocal rate constant, $K_{\mathrm{u}}^{-1}$, versus reciprocal square root of the stirring velocity, $S^{-1 / 2}$, for the methylcellulose solutions. Data for water are from Amidon [14]. The data evidence scatter but are in generally good agreement with an intercept of $7.3 \times 10^{3}$ sec. The ratio of the 100-cp slope to that of water is about 6.3. The lines in order of increasing slope are for methylcellulose $13 \mathrm{cps}(\bullet), 40 \mathrm{cps}(\star)$ and $100 \mathrm{cps}(\mathrm{N})$. The curve for water is labeled as such.

sented for water and the sucrose solutions in Table 4, along with viscosity and density data. Similarly obtained data for the methylcellulose solutions are shown in Table 5 and Fig. 6. These latter data are relatively approximate in nature, due both to difficulties interpreting the viscosity of these nonNewtonian solutions and to variability experienced in estimates of $P$ at the various speeds. 


\section{Discussion}

\section{a. Temperature influence on boundary layer involvement}

As seen from Table 1, temperature studies were performed over a $65^{\circ} \mathrm{C}$ range but there is only a 4.6 fold increase in the apparent permeability coefficient, $P$. No matter what the mechanism, this represents a marked insensitivity to temperature. Moreover, apparent diffusivities, $D_{\mathrm{app}}$, calculated from the Daynes and Barrier lag time relationship, $D=h^{2} / 6 t$, increase 4.61 fold, indicating that the temperature effect is due to increased diffusivity within the barrier system. When the data are plotted in the Arrhenius fashion, $\log K_{\mathrm{n}}$ versus $1 / T$, a curvilinear relationship is obtained as found in Fig. 1 . This vaguely has the general biexponential characteristics expected for a process involving a change from membrane control at low temperature to diffusion layer control at high temperature, and may represent the first temperature related demonstration of such a transition due to differences in activation energy. The break in the curve is so slight, however, that assignment of the activation energies to the respective parts is precluded. Moreover, Hildebrand [19] has called exponential dependencies for diffusivities into question, at least for liquids. This casts doubt over any interpretation of the temperature effects. There is, nevertheless, an interesting aspect to the temperature data. Assuming a change in rate controlling mechanism, $37^{\circ} \mathrm{C}$ appears to be the pivotal temperature, suggesting that the boundary layers are significant here for the $700-\mu \mathrm{m}$ thick membranes, even with the vigorous stirring involved. The apparent diffusivity calculated at $37^{\circ} \mathrm{C}, 4.17 \times 10^{-7} \mathrm{~cm}^{2} / \mathrm{sec}$, agrees well with the value of Roseman [10] (Table 1), but neither may represent accurate estimates of the membrane value due to significant boundary layer involvement. It should be noted that the identical diffusion cell and the essential conditions used by Roseman were employed in these studies.

\section{b. Membrane thickness and boundary layer influence}

The conclusion concerning diffusion layer involvement at $37^{\circ} \mathrm{C}$ is significantly reinforced by data from the membrane thickness dependencies at this temperature. It can be seen from the last column in Table 2 that, as the membrane is made thicker, apparent diffusivities are steadily increasing well past the 500 to $600 \mu \mathrm{m}$ thicknesses previously used for diffusivity estimates [10]. In theory, when the membrane becomes the only significant resistance, the value of the estimated diffusivity should be invarient with further increases in membrane thickness of an isotropic membrane. The permeability coefficient decreases as the thickness increases, but the linear relationship between $P$ and the reciprocal thickness expected for a system in which the membrane is the sole rate controlling element of the barrier system is obviously not observed, as seen in Fig. 3. Rather, the data plotted in this fashion gradually fall away from such an anticipated trend. A best fit computer drawn line based on the membrane-diffusion layer model, expressed mathematically in eqn. (3), is fitted to the data in Fig. 3. This model predicts that the diffusional process 
will be in membrane control when $1 / h_{\mathrm{m}}$ is very small (thick membranes) and in boundary layer control when $1 / h_{\mathrm{m}}$ is very large (thin membranes).

Equation (3) expresses the apparent permeability coefficient, $P$, in terms of fundamental properties of the membrane and the boundary layers. In the limit that the membrane is made infinitely thick, $P$ takes the mathematical form:

$P=\frac{D_{\mathrm{m}} K_{\mathrm{m} / \mathrm{aq}}}{h_{\mathrm{m}}}$

and $\mathrm{d} P / \mathrm{d}\left(1 / h_{\mathrm{m}}\right)$, the tangent to the curve in Fig. 3 as the curve approaches the origin, is equal to $D_{\mathrm{m}} K_{\mathrm{m} / \mathrm{aq}}$. Computer evaluation of the best slope consistent with all the data gives $1.98 \times 10^{-3} \mathrm{~cm}^{2} / \mathrm{min}$ for the value of $D_{\mathrm{m}} K_{\mathrm{m} / \mathrm{aq}}$. Data for the partitioning of progesterone into silicone rubber are reported in Table 3. Based on all estimates, the $K_{\mathrm{m} / \mathrm{aq}}$ value is 47.7 and the membrane diffusivity is thus calculated to be $6.92 \times 10^{-7} \mathrm{~cm}^{2} / \mathrm{sec}$, considerably higher than previous estimates (Table 1) but fully consistent with previous data when it is realized that heretofore all values were without correction for significant boundary layer influences. Roseman [10] indicated that diffusivity within fillerless silicone rubber was $5.78 \times 10^{-7} \mathrm{~cm}^{2} / \mathrm{sec}$ (Table 1), but this too is almost certainly low. Applying the same boundary layer correction factor of $\sim 1.5$ yields a value of $8.7 \times 10^{-7} \mathrm{~cm}^{2} / \mathrm{sec}$, reasonable and in proper proportion to the adjusted value for a membrane containing filler.

As $1 / h_{\mathrm{m}}$ approaches infinity (an infinitely thin membrane), the data reach a plateau, as is expected from the membrane diffusion layer model. The computer projects a limiting value of $4.59 \times 10^{-2} \mathrm{~cm} / \mathrm{min}\left(7.65 \times 10^{-4} \mathrm{~cm} / \mathrm{sec}\right)$, which corresponds to a combined diffusion layer thickness of $91.4 \mu \mathrm{m}$ or, assuming equal contributions, about a $46 \mu \mathrm{m}$ diffusion layer on each side. This exceedingly thin diffusion layer is not surprising since the stirring is vigorous and in close proximity to the membrane surface. A previous estimate of the total boundary layer thickness by Flynn and Yalkowsky [20] for this diffusion cell system was $188 \mu \mathrm{m}$, but was obtained with an ex ternal membrane support in series with the membrane. Their supposition that the support increased the boundary layer thickness seems to have been well founded.

One trial run with a viscid methylcellulose solution of approximately $40 \mathrm{cp}$ was made in the conventional cell, in this case with a $150-\mu \mathrm{m}$ thick membrane. A permeability coefficient of $2.39 \times 10^{-2} \mathrm{~cm} / \mathrm{min}$ was obtained (see Fig. 3), indicating an effective diffusion layer thickness of $140 \mu \mathrm{m}$ (using the aforementioned parameters for the membrane). This is only a 1.53-fold increase over that seen in water, less than the factor of 1.96 predicted from the theoretical sixth root dependency of the diffusion layer thickness with respect to viscosity [18]. A value of $0.710 \mathrm{cp}$ was used for the viscosity of water in this calculation. Despite the lack of a perfect quantitative agreement, which may in part be due to non-Newtonian qualities of the polymer solution under shear, the expected insensitivity of the diffusion layer to macroscopic viscosity is 
amply demonstrated. It is also clear that while viscosity effects on mass transfer could be studied using the conventional cell with computer assisted data analysis, accurate results would depend on the time consuming procedure of making runs at many widely varied membrane thicknesses.

\section{c. Rotating membrane theory}

The rotating diffusion cell described by Albery et al. [16], already being evaluated in these laboratories by Amidon [14], seemed to have built-in advantages for further studies on the hydrodynamic layers. In this apparatus the speed of rotation is easily varied between practical slow and fast extremes (vortexing sets a practical upper limit on velocity of rotation in a given medium). Because of the nature of shear at the flat, rotating membrane surface, the Levich formula for the boundary layer resistance is operative (first term on the right of the equality in eqn. 10). This equation indicates that the boundary layer resistance is dependent on medium kinematic viscosity, $\nu$, to the one-sixth power and permeant diffusivity in the external aqueous medium, $D_{\mathrm{aq}}$, to the negative two-thirds power, as well as rotational speed, $S$, to the negative one-half power. Furthermore and in general, there is an interdependency between diffusivity, $D$, and in medium viscosity, $\xi$, at a given temperature, $T$, set forth in the Stokes-Einstein equation:

$D=\frac{k T}{6 \pi \xi r}$

where $r$ is the molecular radius and $k$ is Boltzmann's constant. It must be kept in mind here that in polymer solutions it is the microscopic viscosity, not the apparent viscosity, which determines the diffusivity. Assuming spherical molecular geometry yields:

$D=\frac{k T}{6 \pi \xi}\left(\frac{4 \pi N_{0} \rho^{\prime}}{3 W}\right)^{1 / 3}$

where $N_{0}$ is Avogadro's number, and $\rho^{\prime}$ the density and $W$ the molecular weight of the permeant. For the present experiments $T=310 \mathrm{~K}, W=314.45$ and $\rho^{\prime} \simeq 1.16$, the crystalline density of progesterone. These values and the measured aqueous viscosity at this temperature of $7.1 \times 10^{-3} \mathrm{p}$, when placed into eqn. (14), yield a highly reasonable aqueous diffusivity at $37^{\circ} \mathrm{C}$ for progesterone of $6.73 \times 10^{-6} \mathrm{~cm}^{2} / \mathrm{sec}$, almost ten times the computer estimate of the diffusivity of progesterone in the silicone rubber membranes.

The viscosity in eqns. (13) and (14) is in centipoise units $\left(\mathrm{g}-\mathrm{cm}^{-1}-\mathrm{sec}^{-1}\right)$. Equation (14), which allows ab initio calculation of diffusion coefficients, can be merged with eqn. (9) once the different viscosities comprising the StokesEinstein and Levich expressions are made compatible. The relationship between viscosity and kinematic viscosity is: 
where $\nu$ is the kinematic viscosity in centistokes $\left(\mathrm{cm}^{2}-\mathrm{sec}^{-1}\right)$ and $\rho$ is the density of the liquid medium. The boundary layer expression in terms of the permeability coefficient (reciprocal of resistance) of each hydrodynamic layer (see eqn. 10) becomes:

$P_{\mathrm{aq}}=\frac{1}{R_{\mathrm{aq}}}=1.557\left(\frac{k T}{6 \pi}\right)^{2 / 3}\left(\frac{4 \pi N_{0} \rho^{\prime}}{3 W}\right)^{2 / 9} \xi^{-5 / 6} p^{1 / 6} S^{1 / 2}$

where $S$ is the rotational speed in revolutions per second.

Letting the term $\alpha$ represent the collected constants in eqn. (16), i.e.:

$\alpha=1.557\left(\frac{k}{6 \pi}\right)^{2 / 3}\left(\frac{4 \pi N_{0}}{3}\right)^{2 / 9}=1.55 \times 10^{-6}$

and recognizing that

$\frac{1}{K_{\mathrm{u}}}=\frac{V_{\mathrm{d}}}{A}\left(\frac{2}{P_{\mathrm{aq}}}+\frac{1}{P_{\mathrm{m}}}\right)$

is a form of eqn. (11), it follows that the reciprocal rate constant is related to stirring and other variables through:

$\frac{1}{K_{\mathrm{u}}}=\left(\frac{2 V_{\mathrm{d}} W^{2 / 9} \xi^{5 / 6}}{\alpha A T^{2 / 3} \rho^{\prime 2 / 9} \rho^{1 / 6}}\right) S^{-1 / 2}+\frac{V_{\mathrm{d}}}{A P_{\mathrm{m}}}$

The theoretical slope of a plot of $1 / K_{\mathrm{u}}$ versus $1 / S^{1 / 2}$ therefore is:

$$
\frac{2 V_{\mathrm{d}} W^{2 / 9} \xi^{5 / 6}}{\alpha A T^{2 / 3} \rho^{\prime 2 / 9} \rho^{1 / 6}}
$$

\section{d. Viscosity effects as seen with rotating membranes}

The sucrose solutions were essentially Newtonian in behavior and linearity of $1 / K_{u}$ versus $1 / S^{1 / 2}$ plots, a measure of agreement between theory and experiment, was expected (Fig. 5). The data for methylcellulose solutions also roughly followed the Levich stirring velocity dependency, despite the fact that these were non-Newtonian (Fig. 6). It should be noted that in both sets of data the intercept value is either known by independent calculation (water and methylcellulose solutions only) or can be estimated sufficiently for plotting purposes (sucrose solutions). In aqueous systems, including the highly dilute methylcellulose solutions, the intercept would be:

$$
\frac{V_{\mathrm{d}}}{A P_{\mathrm{m}}}=\frac{V_{\mathrm{d}}}{A}\left(\frac{h_{\mathrm{m}}}{D_{\mathrm{m}} K_{\mathrm{m} / \mathrm{aq}}}\right)
$$

$D_{\mathrm{m}}$ and $K_{\mathrm{m} / \mathrm{aq}}$ were previously determined to be $6.92 \times 10^{-7} \mathrm{~cm}^{2} / \mathrm{sec}$ and 47.7 , respectively. In the rotating membrane experiments the membrane thickness was $150 \mu \mathrm{m}$ and $V_{\mathrm{d}}$ the donor volume of $70 \mathrm{~cm}^{3}$ as the process was fol- 
lowed as a loss in concentration from this compartment. Thus the intercept should be $7.3 \times 10^{3} \mathrm{sec}$. This intercept, which corresponds to infinitely fast rotational velocity, is nearly imperceptible for water on the scale of Fig. 5. For the sucrose solutions the intercept would be even smaller as progesterone is driven out of solution by sucrose addition, making the partition coefficient larger. All sucrose solution data sets seem to extrapolate comfortably through the essentially 0,0 intercept and are, in this regard, in good agreement with theory. The water and methylcellulose data are consistent with the independently estimated intercept, not negligible on the scale of Fig. 6 , of $7.3 \times 10^{3}$ sec.

Amidon [14] has demonstrated that the rotating membrane diffusion apparatus is adequate to measure boundary layer characteristics, even when the solvent medium is pure water, under circumstances where the permeant is progesterone and the membrane is a thin polydimethylsiloxane film. The system becomes exquisitely sensitive to the boundary layer when the medium viscosity is increased over that of water, as seen in Figs. 5 and 6 . Two system dependencies on viscosity of essentially different origins are involved as viscosity is raised. There is first an expected "thickening" of the hydrodynamic layer due to the increased viscous drag at the rotating surface. This is over and above medium effects on diffusivity as given in the Stokes-Einstein formulation. Equations (11) and (13) together indicate that the effect of viscosity on diffusivity should be the more significant one. Indeed, a 64 -fold increase in kinematic viscosity is required to double the diffusional resistance if there is no concomitant effect on diffusivity. An important point of understanding here is that the viscosity determining the magnitude of the diffusion coefficient is the microscopic (molecular level) viscosity of the system or the viscosity resulting from primary inter-molecular forces. When a polymer is present, the physical entanglement of its strands can impart a high gross viscosity without much effect on the system's microscopic property. This should essentially be the case at the low concentrations of methylcellulose used in the present experiments where effects should be almost strictly on boundary layer thickness. It is therefore expected that methylcellulose solutions will exhibit substantially smaller hydrodynamic resistances than isoviscid sucrose solutions under circumstances where viscosity is based on macroscopic measurements.

The general patterns of permeability dependency on viscosity suggested above were all semi-quantitatively born out. Increasing the viscosity and density of the media by the addition of sucrose caused a striking increase in the slopes of the plots of $1 / K_{u}$ versus $1 / S^{1 / 2}$. At $23.5 \mathrm{cp}$ viscosity, the slope is about 35 times that seen in water. The expected effect if viscosity alone were a factor would be 1.79 (last two columns of Table 4), showing that diffusivity is overwhelmingly important. A similar conclusion is reached at each of the other sucrose concentrations. The quantitative agreement between experiment and theory in the sucrose solutions is off by a factor of two at all sucrose concentrations (column 6 of Table 4). At this point it is not possible to determine where the inexactness lies. For pure water, the agreement be- 
tween theory and experiment is very tight. Of greatest importance, in the $60 \%$ sucrose solution the boundary layer is over 100 times more resistant than the membrane at what seems a vigorous stirring velocity of 1 revolution per second, even when the $o / w$ partition coefficient decreases caused by sucrose are not taken into account. The boundary layer involvement is less, but still very large at faster stirring and in the more dilute solutions.

When the viscosity is increased systematically with methylcellulose a very different pattern emerges. In this case, at a viscosity of about $100 \mathrm{cp}$ the slope is only 6.1 times that seen with pure water. This is fully 25 times less than expected based on eqn. (20), which includes the Stokes-Einstein effect of viscosity on diffusivity, but is about 2.7 times the value if diffusivity were actually invarient (last two columns of Table 5). It appears, therefore, that there is either a small effect on diffusivity or a more complex viscosity dependency to this rotating membrane situation than evident in the Levich equation. The important fact is that the thickening caused by a polymeric substance has a relatively nominal effect on mass transfer. Diffusivity cannot be represented by the Stokes-Einstein formula for these polymeric media.

\section{References}

1 B.E. Lukie, H. Westergaard and J.M. Dietchy, Validation of a chamber that allows measurement of both tissue uptake rates and unstirred layer thicknesses in the intestine under conditions of controlled stirring, Gastroenterology, 67 (1974) 652.

$2 \mathrm{H}$. Westergaard and J.M. Dietchy, Delineation of dimensions and permeability characteristics of two major diffusion barriers to passive mucosal uptake in the rabbit intestine, J. Clin. Invest., 54 (1974) 718.

3 D. Winne, in: M. Kramer and F. Lauterbach (Eds.), Intestinal Permeation, Excerpta Medica, Amsterdam, The Netherlands, 1977, pp. 58-64.

4 N.F.H. Ho, J.Y. Park, W. Morozowich and W.I. Higuchi, in: E.B. Roche (Ed.), Design of Biopharmaceutical Properties Through Prodrugs and Analogs, American Pharmaceutical Association, Academy of Pharmaceutical Science, Washington, D.C., 1977 , pp. 136-227.

5 G.L. Flynn, S.H. Yalkowsky and T.J. Roseman, Mass transport phenomena and models - Theoretical aspects, J. Pharm. Sci., 63 (1974) 479.

6 W.I. Higuchi, N.F.H. Ho, J.Y. Park and I. Komiga, Rate-limiting steps and factors in drug absorption, in: L.F. Prescott and W.S. Nimmo (Eds.), Drug Absorption, Adis Press, New York, NY, 1981, p. 35.

7 R.J. Scheuplein, Mechanism of percutaneous absorption. II. Transient diffusion and the relative importance of various routes of skin penetration, J. Invest. Derm., $48(1967) 79$.

8 G.L. Flynn, H. Durrheim and W.I. Higuchi, Permeation of hairless mouse skin. II. Membrane sectioning techniques and influences on alkanol permeabilities, J. Pharm. Sci., 70 (1981) 52.

9 S. Farber, Some organic digestive disturbances early in life, Mich. St. Med. Soc. J., 44 (1945) 587.

10 T.J. Roseman, Release of steroids from a silicone rubber, J. Pharm. Sci., 61 (1972) 46.

11 A.S. Michaels, P. Wong, R. Prather and R. Gale, A thermodynamic method of predicting the transport of steroids in polymer matrices, AIChE J., 21 (1975) 1073.

12 E.R. Garrett and R.B. Chemburkar, Evaluation, control, and prediction of drug diffusion through polymeric membranes. I. Methods and reproducibility of steadystate diffusion studies, J. Pharm. Sci., 57 (1968) 944. 
13 E.G. Lovering and D.B. Black, Drug permeation through membranes. I. Effects of various substances on amobarbital permeation through polydimethylsiloxane, J. Pharm. Sci., 62 (1973) 602.

14 G.E. Amidon, W.I. Higuchi and N.F.H. Ho, Theoretical and experimental studies of micelle-solubilized solutes, J. Pharm. Sci., 71 (1982) 77.

15 G.L. Flynn and E.W. Smith, Membrane diffusion. I. Design and testing of a new multifeatured diffusion cell, J. Pharm. Sci., 60 (1971) 1713.

16 W.J. Albery, J.F. Burke, E.B. Leffler and J. Hadgraft, Interfacial transfer studies with a rotating diffusion cell, J. Chem. Soc., 72 (1976) 1618.

17 Methylcellulose ethers in aqueous systems for tablet coating, Brochure, The Dow Chemical Company, Miidland, MI 48640.

18 V.G. Levich, Physicochemical Hydrodynamics, Prentice Hall, Englewood Cliffs, NJ, 1962, p. 69.

19 J.H. Hildebrand, Viscosity and Diffusivity, Wiley, NY, 1977, pp. 1-7.

20 G.L. Flynn and S.H. Yalkowsky, Correlation and prediction of mass transport across membranes I. Influence of alkyl chain length on the flux determining properties of barrier and diffusant, J. Pharm. Sci., 61 (1972) 838 . 